\title{
PERANCANGAN SISTEM DISTRIBUSI ZONA II TANJUNG BALAI KARIMUN KEPULAUAN RIAU
}

\author{
Ivan Cahya Raswoko ${ }^{1, a}$, Syamsir Abduh ${ }^{2, b}$, Maula Sukmawidjaja ${ }^{3, c}$ \\ 1 Jurusan Teknik Elektro Fakultas Teknologi Industri Universitas Trisakti, Indonesia \\ ${ }^{2}$ Lembaga Penelitian Universitas Trisakti \\ a raswoko31@gmail.com
}

\begin{abstract}
Abstrak.
Sistem distribusi merupakan salah satu elemen yang paling penting untuk dapat meyalurkan energi listrik dari pembangkit ke konsumen. Tanjung Balai Karimun, Kepulauan Riau merupakan sebuah pulau yang berada di dekat pulau Batam. PT Karimun Power Plant telah membangun pembangkit dengan kapasitas total 7.5 MW yang terdiri dari 5 mesin dengan kapasitas masing-masing $1.5 \mathrm{MW}$. Penelitian ini tertuju pada sistem distribusi yang sesuai untuk diterapkan disana. Saluran udara tegangan menengah merupakan salah satu sistem yang ada, dan cocok untuk diterapkan di Zona II Tanjung Balai Karimun Kepulauan Riau. Ukuran penampang yang digunakan pada saluran yang telah dihitung adalah $100 \mathrm{~mm}^{2}$ pada hulu dan $16 \mathrm{~mm}^{2}$ pada hilir. Pengahantar-penghantar ini ditopang oleh tiang dengan ketinggian $12 \mathrm{~m}$ dan dengan jarak antar tiang selebar $100 \mathrm{~m}$. dalam sistem ini juga terdapat transformator dengan kapasitas 160 - $4000 \mathrm{kVA}$. Sistem ini di uji menggunakan software ETAP dan menghasilkan data bahwa pembangkit yang tersedia tidak cukup untuk memikul beban yang ada di Zona II Tanjung Balai Karimun. Dikarenakan tidak memadainya pembangkit yang ada maka solusinya jangka panjangnya adalah untuk menambah jumlah pembangkit sedangkan solusi jangka pendeknya adalah dengan mengurangi beban yang akan di pikul.
\end{abstract}

Kata kunci. SUTM, Sistem Distribusi, ETAP

\begin{abstract}
.
The distribution system is one of the most important elements to be able to distribute electrical energy from power plants to consumers. Tanjung Balai Karimun, Kepulauan Riau is an island near the island of Batam. PT Karimun Power Plant has built a plant with a total capacity of $7.5 \mathrm{MW}$ consisting of 5 machines with a capacity of $1.5 \mathrm{MW}$ each. This research is aimed at the appropriate distribution system to be applied there. Medium voltage air duct is one of the existing systems, and is suitable to be applied in Zone II Tanjung Balai Karimun Riau Islands. The cross section size used in the calculated conduit is $100 \mathrm{~mm}^{2}$ in the upstream and $16 \mathrm{~mm}^{2}$ in the downstream. These conveyors are supported by a pole with a height of $12 \mathrm{~m}$ and with a distance between the poles as wide as $100 \mathrm{~m}$. in this system there is also a transformer with a capacity of 160-4000 kVA. This system was tested using ETAP software and produced data that the available generator was not enough to carry the burden in Zone II Tanjung Balai Karimun. Due to inadequate power generation, the long-term solution is to increase the number of plants while the short-term solution is to reduce the burden to be carried.
\end{abstract}

Keywords. SUTM, Sistem Distribusi, ETAP

\section{PENDAHULUAN}

Dalam melaukukan kegiatan sehari-hari masyarakat tidak lepas dari kebutuhannya akan listrik. Listrik merupakan salah satu energi yang sangat berguna bagi semua kalangan. Dari rumah tangga, perkantoran sampai perindustrian energi listrik pasti dibutuhkan. Salah satu bagian dari proses penyediaan energi listrik bagi konsumen adalah jaringan distribusi. Jaringan distribusi adalah bagian penting yang tidak boleh dipinggirkan, jaringan distribusi merupakan perantara utama antara pembangkit energi listrik dengan konsumen atau pemakai. 
Tanjung Balai Karimun merupakan sebuah pulau yang berada di Kepulauan Riau. Pulau ini merupakan salah satu pulau Indonesia yang berada paling luar dan berbatasan dengan Singapore. Di pulau ini terdapat daerah perindustrian pada salah satu sisi pulau, bidang usaha utama dari perindustrian yang berada dipulau ini adalah pertambang batu granit. Selain bidang usaha pertambang batu granit terdapat juga perindustrian pada bidang usaha gas acetilin dan galangan kapal.

Terdapat suatu hal yang menarik dari pulau ini. Pulau ini dibagi menjadi tiga zona dalam hal hak pemasok listriknya seperti yang dapat dilihat pada Gambar 1. Di Zona I hak dipegang oleh PT. Soma Daya Utama (PT. SDU), di Zona II hak dipegang oleh PT Karimun Power Plant (PT. KPP) dan di Zona III hak dipegang oleh pihak PT. Perusahaan Listrik Negara (PT. PLN).

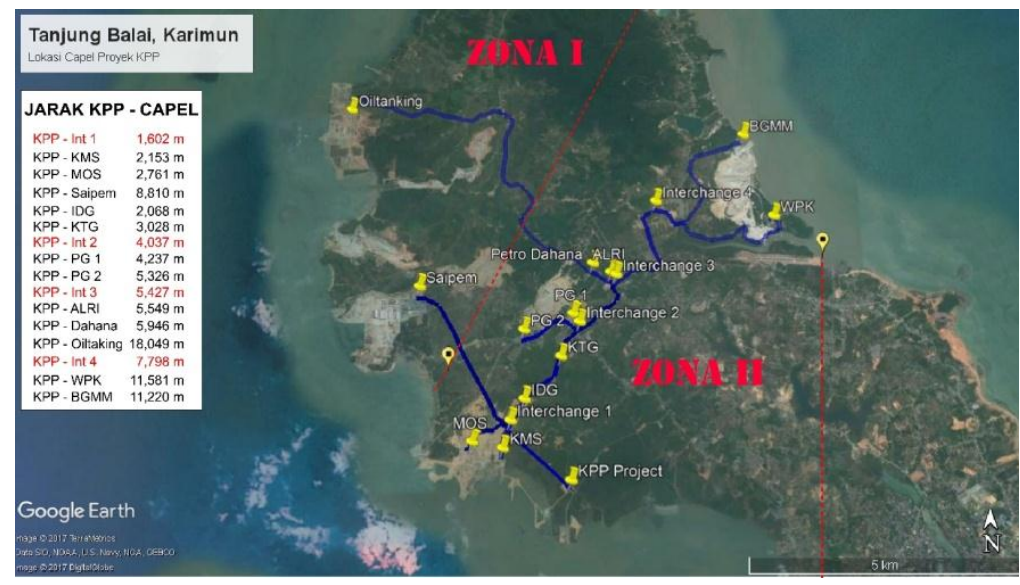

Gambar 1. Pembagian Zona Pulau Karimun, Kepulauan Riau

Di zona II PT. KPP bekerjasama dengan PT. Widar Mandripa Nusantara (PT. WMN) dalam membangun pembangkit energi listrik bertenaga gas untuk keperluan energi listrik di zona II. PT. KPP yang bekerjasama dengan PT. WMN berusaha memberikan pilihan sumber energi listrik baru bagi perindustrian disana. Kedua perusahaan ini telah membangun pembangkit energi listrik bertenaga gas sebanyak 5 unit dengan masing-masing berkapasitas $1.5 \mathrm{MW}$.

Meskipun PT. KPP yang bekerjasama dengan PT. WMN telah membangun pembangkit listrik bertenaga gas yang terdiri dari 5 buah mesin gas yang masing masing berdaya 1,5 MW, namun jalur distribusi listrik di wilayah ini belum tersedia untuk menyambungkan antara sisi pembangkit dengan konsumen. Maka dari itu penelitian ini akan merancang jalur distribusi di Zona II Tanjung Balai Karimun, Kepulauan Riau.

\section{Studi Pustaka}

Sistem distribusi adalah sebuah sistem yang berguna untuk menyalurkan daya dari pembangkit sampai ke konsumen. Dalam sistem penyaluran energi listrik terdapat dua bagian, yaitu sistem distribusi dan sistem transmisi. Jaringan distribusi berbeda dengan jaringan transmisi. Secara garis besar sistem transmisi merupakan sistem yang menyalurkan energi listrik unutk jarak yang sangat jauh, sedangkan jaringan distribusi untuk jarak yang lebih dekat.

Sistem distribusi dapat digolongkan berdasarkan tegangannya dan jenis konstruksinya. Berdasarkan tegangannya, sistem distribusi dibagi menjadi tegangan tinggi, tegangan menengah dan tegangan rendah. Sedangkan berdasarkan konstruksinya, sistem distribusi dibagi menjadi saluran udara dan saluran bawah tanah.

\section{Berdasarkan Tegangan}

a. Tegangan Tinggi

Tegangan tinggi digunakan dalam menyalurkan daya dengan jarak yang jauh. Tegangan tinggi di indonesia menggunakan tegangan $70 \mathrm{kV}, 150 \mathrm{kV}$ dan $275 \mathrm{kV}$. 
b. Tegangan Menengah

Tegangan menengah di Indonesia menggunakan tegangan antara $6 \mathrm{kV}$ sampai $20 \mathrm{kV}$. Tegangan menengah pada umumnya digunakan untuk keperluan industri dan digunakan untuk saluran distribusi primer di perkotaan.

c. Tegangan Rendah

Tegangan rendah di Indonesia menggunakan tegangan $380 \mathrm{~V}$ dan $220 \mathrm{~V}$. Tegangan rendah ini digunakan dalam saluran distribusi sekunder yaitu saluran distribusi untuk pemkaian listrik rumah tangga.

\section{Berdasarkan Konstruksi}

a. Saluran Udara

Jalur distribusi degan konstruksi saluran udara adalah saluran dengan penghantarnya berada di udara dengan ditopang oleh tiang. Penghatar di saluran udara biasanya menggunakan penghatar telanjang yaitu penghantar tanpa isolasi. Saluran udara memiliki beberapa kelebihan, diantaranya:

1. Biaya pembangunan atau investasi yang jauh lebih rendah dibandingkan konstruksi bawah tanah.

2. Untuk daerah dengan dataran bebatuan lebih mudah untuk membuat lubang untuk tiang listrik dibandingkan membuat jalur untuk bawah tanah.

b. Saluran Bawah Tanah

Jalur distribusi dangan konstruksi bawah tanah adalah suatu saluran distribusi yang menggunakan penghantar berisolasi penuh dan di tanam didalam tanah. Saluran bawah tanah memiliki beberapa kelebihan, diantaranya:

1. Dari segi estetika, jalur distribusi dengan konstruksi bawah tanah memiliki nilai yang baik karena berada dibawah tanah dan tidak terlihat sehingga cocok untuk di perkotaan yang penduduknya padat serta padat lalu-lintasnya.

2. Keandalan dari jalur distribusi dengan menggunakan konstruksi bawah tanah lebih tinggi karena tidak terpengaruh oleh hujan, petir, angin ribut maupun faktor alam lainnya.

Pada sistem distribusi terdapat beberapa komponen yang perlu diketahui seperti berikut ini:

a. Transformator

Transformator merupakan alat yang berguna untuk menaikkan atau menurunkan tegangan. Salah satu tujuan tegangan perlu dinaikkan atau diturunkan adalah untuk membuat penggunaan penghantar lebih hemat. Transformator biasa diletakkan pada sisi sebelum masuk ke pelanggan. Penentuan dari pemilihan transformator adalah dari daya yang akan dialirkan ke beban, dan dapat dicari menggunakan rumus sebagai berikut:

$$
\mathrm{S}=\mathrm{P} \times \cos \varphi
$$

Dimana : $\mathrm{S}$ = Daya untuk kapasitas transformator $(\mathrm{VA})$

$$
\mathrm{P}=\text { Daya }(\text { Watt })
$$

b. Penghantar

Penghatar merupakan media utama bagi energi listrik mengalir, penghantar listrik ada bermacam-macam namun pada sistem distribusi menggunakan kabel. Dalam menentukan kabel yang dibutuhkan pada sistem distribusi, diperlukan nilai arus yang mengalir pada sistem tersebut. Nilai arus tersebut dapat dicari menggunakan rumus sebagai berikut:

$$
\mathrm{I}=\mathrm{P} /(\mathrm{V} \times \sqrt{3} \times \cos \varphi)
$$

$$
\begin{aligned}
& \text { Dimana }: \mathrm{I}=\text { Arus (Ampere) } \\
& \mathrm{P}=\text { Daya (Watt) } \\
& \mathrm{V}=\text { Tegangan }(\text { Volt })
\end{aligned}
$$


c. Tiang

Tiang penyangga ini berfungsi untuk menopang penghantar yang berada di udara. Berdasarkan puil, persyaratan dari suatu tiang penyangga dipengaruhi oleh tegangan saluran yang digunakan. Untuk distribusi tegangan menengah dengan tegangan $6-30 \mathrm{kV}$, tinggi tiang yang ditentukan setinggi 10-20 m dan untuk jarak antar tiang selebar 60-150 m.

Berdasarkan data yang diperoleh dari PT. Widar Mandripa Nusantara, diketahui pelanggan yang terdapat di Zona II Tanjung Balai Karimun, Kepulauan Riau memiliki kebutuhan daya seperti pada Tabel 1 berikut ini

Tabel 1. Beban Pelanggan

\begin{tabular}{ll}
\hline Pelanggan & Daya $(\mathrm{kW})$ \\
\hline KMS & 600 \\
MOS & 2170 \\
IDG & 90 \\
KTG & 250 \\
PG & 2969 \\
ALRI & 400 \\
PD & 552 \\
WPK & 984 \\
BGMM & 823 \\
\hline
\end{tabular}

\section{METODOLOGI PENELITIAN}

Untuk merancang suatu sistem distribusi, maka diperlukan langkah-langkah yang terdapat dalam diagram alir dibawah ini:

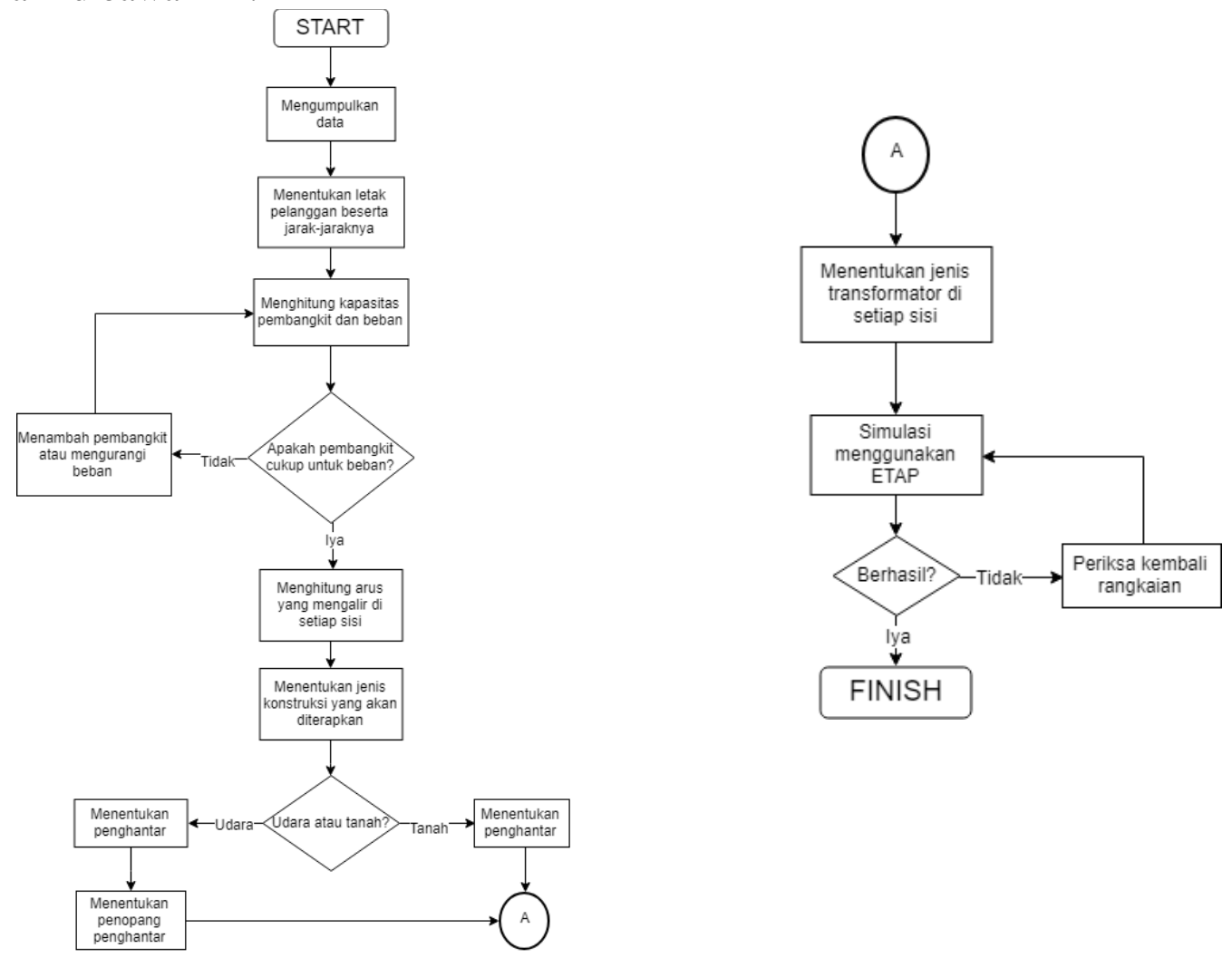

Gambar 2. Diagram Alir Penelitian 


\section{HASIL, PEMBAHASAN DAN ANALISA}

\section{Pemilihan Sistem Distribusi}

Dari pertimbangan yang dilakukan untuk sistem distribusi yang sesuai diterapkan di Zona II Tanjung Balai Karimun, Kepulauan Riau maka saluran udara dengan menggunakan tegangan menengah adalah yang sesuai untuk diterapkan. Hal ini didasari oleh:

1. Kawasan disana merupakan kawasan industri sehingga faktor estetika bukan hal yang di utamakan

2. Kawasan disana memiliki tektur daratan yang bayak bebatuan sehingga sulit untuk melakukan penggalian jika ingin menggunakan jalur bawah tanah

3. Tegangan menegah digunakan agar mengesilkan nilai arus yang lewat saat pendistribusian.

\section{Perhitungan Arus Setiap Sisi}

Untuk perhitungan arus, digunakan rumus 2 untuk mendapatkan hasilnya. Seperti misalnya mencari untuk arus pada PT. KMS seperti berikut ini:

$$
\mathrm{I}=600000 /(20000 \times \sqrt{3} \times 0.85)=20.37 \mathrm{~A}
$$

Untuk pelanggan lain dilakukan sama seperti diatas dan hasil akhir akan seperti Tabel 2 pada kolom arus

\section{Perhitungan Kapasitas Transformator Setiap Sisi}

Untuk perhitungan kapasitas transformator, digunakan rumus 1 untuk mendapatkan hasilnya. Seperti misalna untuk kapasitas transformator pada PT. KMS seperti berikut ini:

$$
\mathrm{S}=600000 \times 0.85=510 \mathrm{kVA}
$$

Untuk pelanggan lain dilakukan sama seperti diatas dan hasil akhir akan seperti Tabel 2 pada kolom kapasitas transformator. Nilai tersebut sudah menjadi nilai yang sudah umum di lapangan.

Tabel 2. Hasil Akhir Perhitungan

\begin{tabular}{lll}
\hline Pelanggan & Arus (A) & $\begin{array}{l}\text { Kapasitas } \\
\text { Transformator } \\
\text { (kVA) }\end{array}$ \\
\hline KMS & 20.37 & 630 \\
MOS & 73.69 & 3600 \\
IDG & 3.05 & 100 \\
KTG & 8.49 & 250 \\
PG & 100.83 & 3600 \\
ALRI & 13.58 & 400 \\
PD & 18.67 & 630 \\
WPK & 33.41 & 1000 \\
BGMM & 27.95 & 1000 \\
\hline
\end{tabular}

\section{Pemilihan Kabel}

Pemilihan kabel dilakukan berdasarkan arus yang telah dicari. Untuk saluran udara menggunakan penghantar jenis AAAC dengan luas penampang yang berbeda-beda. Perbedaan ini ditentukan sesuai katalog dari suatu produsen dan hasilnya seperti pada Tabel 3

\section{Perhitungan Jumlah Tiang}

Untuk menghitung kebutuhan tiang dapat melakukan perhitungan dengancara membagi jarak dengan 100. Hal ini karena standar jarak antar tiang adalah $100 \mathrm{~m}$. hasilnya dapat dilihat pada tabel 3. Hasil ini telah dibulatkan keatas. 
Tabel 3 Hasil Akhir Perhitungan

\begin{tabular}{llll}
\hline Objek & $\begin{array}{l}\text { Luas } \\
\left(\mathrm{mm}^{2}\right)\end{array}$ & Penampang & $\begin{array}{l}\text { Keperluan Tiang } \\
(\mathrm{pcs})\end{array}$ \\
\hline KPP-INT1 & 100 & 17 \\
INT1-KMS & 16 & 6 \\
INT1-MOS & 16 & 12 \\
INT1-INT2 & 70 & 26 \\
INT2-PG & 25 & 2 \\
INT2-INT3 & 25 & 14 \\
INT3-ALRI & 16 & 2 \\
ALRI-PD & 16 & 4 \\
INT3-INT4 & 16 & 24 \\
INT4-WPK & 16 & 38 \\
INT4-BGMM & 16 & 35 \\
\hline
\end{tabular}

\section{Simulasi Dengan ETAP}

Sistem yang telah dirancang tersebut telah di simulasikan menggunakan ETAP dan menghasilkan data bahwa pembangkit yang tersedia tidak cukup untuk memikul beban yang ada di Zona II Tanjung Balai Karimun sehingga harus dilakukan pengurangan beban atau penambahan kapasitas pembangkit.

\section{KESIMPULAN}

Berisikan kesimpulan penelitian yang ditulis:

1. Sistem distribusi yang sesuai untuk diterapkan di Zona II Tanjung Balai Karimun, Kepulauan Riau adalah saluran udara tegangan menengah dengan menggunakan tegangan $20 \mathrm{kV}$ dan penghantar dengan ukuran penampang mulai dari $100 \mathrm{~mm}^{2}$ pada hulu dan $16 \mathrm{~mm}^{2}$ pada hilir.

2. Sistem distribusi saluran udara tegangan menengah yang dirancang untuk Zona II Tanjung Balai Karimun, Kepulauan Riau menggunakan:

a. Tiang-tiang penopang dengan tinggi $12 \mathrm{~m}$ dan jarak antar tiang $100 \mathrm{~m}$ berjumlah 180 buah

b. Transformator dengan kapasitas $160-4000 \mathrm{kVA}$ berjumlah 9 buah

c. Penghantar dengan luas penampang $16-100 \mathrm{~mm}^{2}$ sepanjang $17,432 \mathrm{~m}$

\section{DAFTAR PUSTAKA}

1 .

Buku 5 PLN, 2010,

Standar Konstruksi Jaringan Tegangan Menengah Tenaga Listrik, PLN, Jakarta

2.

Distribusi dan Utilitasi Tenaga Listrik, Universitas Indonesia, Jakarta

Kadir Abdul, 2006,

3.

Survei Karakteristik Beban Kelistrikan di Zona II, feasibility study PT KPP

Michael Pike, 2016,

4. Suswanto Daman, 2009, Sistem Distribusi Tenaga Listrik, Universitas Padang, Padang.

5. Annisa Nur Wahyuni, Lydia Anggraini, "Prospek Bisnis dengan Teknologi DSSL (Dry Sludge Synthetic Lubricant) sebagai Solusi Pengurangan Sludge Limbah B3 (Berbahaya dan Beracun) Sekaligus Peluang Benefit Wax (C20+) sebagai Synthetic Lubricant." Prosiding Seminar Nasional Cendekiawan. 